www.nature.com/pj

\title{
Influence of maleic anhydride grafted polypropylene on the dispersion of clay in polypropylene/clay nanocomposites
}

\author{
Weiheng Yuan, Min Guo, Zhuang Miao and Yiqun Liu
}

This paper investigates the specific effect of the maleic anhydride (MA) grafting content of MA-grafted polypropylene (PP-g-MA) compatibilizer on the morphology of PP/clay nanocomposites (PPCNs) without the interference of molecular weight (MW) changes of the compatibilizer. To do this, PP-g-MA with different grafting contents and approximately the same MW was prepared using MA and styrene by melt extrusion on a twin-screw extruder. The two prepared series of PP-g-MA were used, respectively, in two series of PPCN based on PP homopolymer and impact copolymer to match the melt flow rate of the compatibilizer with that of the PP matrix. The morphology observations from X-ray diffraction and transmission electron microscopy, as well as rheological measurements, showed that the grafting content of PP-g-MA in the range of 0.2-1.4wt\% has no appreciable influence on the dispersion of organoclay, whereas the loading of PP-g-MA can effectively influence the intercalation and delamination of clay. The intercalation and exfoliation mechanism of prepared PP-g-MA is discussed and compared with that of PP-g-MA oligomer.

Polymer Journal (2010) 42, 745-751; doi:10.1038/pj.2010.68; published online 28 July 2010

Keywords: grafting content; maleic anhydride; polypropylene

\section{INTRODUCTION}

Polymer/clay composites can be divided into three general types, namely, phase-separated, intercalated and exfoliated nanocomposites. ${ }^{1}$ However, it is difficult, to obtain well-dispersed and fully exfoliated clay particles in a nonpolar polypropylene (PP) matrix because of the incompatibility between PP and clay. This has been an obstacle in the preparation of high-performance $\mathrm{PP} /$ clay nanocomposite (PPCN). Some compatibilizers that have been used to obtain better mechanical properties have become an indispensable component of PPCN.

Studies on the effect of compatibilizers on clay intercalation and exfoliation involve various PPCN-related aspects, such as different grafted functional groups, ${ }^{2,3}$ grafting position, ${ }^{4}$ grafting content ${ }^{5-12}$ and compatibilizer loading. ${ }^{13-15}$ In these studies, polypropylenegrafted maleic anhydride (PP-g-MA) oligomer is usually chosen as the compatibilizer. ${ }^{2,5,6,15,16}$ However, the addition of PP-g-MA oligomer deteriorates mechanical properties, especially at a higher loading, ${ }^{10,12,15}$ whereas PP-g-MA compatibilizer with high molecular weight ((HMW) PP-g-MA) does not cause such deterioration. ${ }^{7,12}$ Grafting content and MW are two important parameters of PP-g-MA compatibilizer. It is of great value to industry to investigate the effect of these two parameters on the dispersion of clay and mechanical properties of PPCN. To date, the research results on the effect of MA grafting content on clay intercalation and the mechanical properties of PPCN have been based on either comparison among different
PP-g-MA oligomers ${ }^{5,6,15,16}$ or comparison between PP-g-MA oligomer and HMW PP-g-MA. ${ }^{7-10,12}$ The differences in MW in those compatibilizers are seldom considered when discussing the influence of grafting content on clay dispersion. It is thus quite necessary to elucidate the specific effect of the MA grafting content of the compatibilizer on the morphology and properties of PPCN without the interference of MW changes in the compatibilizer.

The purpose of this paper is to investigate the effect of grafting content and loading of PP-g-MA compatibilizer with relatively HMW on clay dispersion in PPCN. We prepared two series of HMW PP-g-MA compatibilizers with different MA grafting contents and of approximately the same MW and melt flow rate (MFR) through melt extrusion grafting on a twin-screw extruder by controlling the initiator concentration and the loading of the grafting monomer and comonomer. Because the prepared PP-g-MA compatibilizers have approximately the same MW and MFR, the influence of MW can be separated from that of grafting content.

\section{MATERIALS AND METHODS}

Materials

The organoclay called Nanomer I.44P was supplied by Nanocor (Chicago, IL, USA). It is a montmorillonite modified with a quaternary ammonium salt (OMMT). Two powdered PP homopolymers (homo-PP), namely, TC-1 (weight average MW, $M_{\mathrm{w}}=459100$, number average MW, $M_{\mathrm{n}}=61000$, 
$\mathrm{MFR}=1 \mathrm{~g}$ per $10 \mathrm{~min}$ at $\left.230^{\circ} \mathrm{C}\right)$ and TC-3 $\left(M_{\mathrm{w}}=319000, M_{\mathrm{n}}=57000\right.$, $\mathrm{MFR}=5 \mathrm{~g}$ per $10 \mathrm{~min}$ at $230^{\circ} \mathrm{C}$ ), were supplied by Blue-Star Petrochemical, Tianjin, China. The PP impact copolymer in pellet form (polypropylene hetro copolymer, heco-PP), $\mathrm{K} 9015$ (MFR $=15 \mathrm{~g}$ per $10 \mathrm{~min}$ at $230^{\circ} \mathrm{C}$ ), was supplied by SINOPEC Yangzi Petrochemical, Beijing, China. The AR-grade MA was supplied by Beijing Yili Fine Chemical, Beijing, China. 2-Dodecen-1-ylsuccinic anhydride was obtained from Acros Organics (Morris Plains, NJ, USA). HMW PP-g-MA was self-made. Dicumylperoxide (DCP) was obtained from the Beijing Duxin Fine Chemical Factory, Beijing, China.

\section{Preparation of PPCNs}

All PP-g-MA compatibilizers used in this research were self-made using a melt grafting method because commercial PP-g-MA with different grafting contents but similar MW is not available. Melt extrusion grafting reactions were carried out in a Thermo Haake Polylab OS intermeshing corotating twin-screw extruder (diameter $16 \mathrm{~mm}, \mathrm{~L} / \mathrm{D}=40: 1$; Thermo Electron (Karlsruhe) $\mathrm{GmbH}$, Karlsruhe, Germany) at $190^{\circ} \mathrm{C}$ and 100 r.p.m.

Two series of PP/OMMT nanocomposites based on homo-PP and heco-PP were prepared using the above-mentioned twin-screw extruder at $190^{\circ} \mathrm{C}$ and 200 r.p.m. The exact specifications are listed in Table 2, and all ratios are based on weight. OMMT was dried at $90^{\circ} \mathrm{C}$ for $12 \mathrm{~h}$ in a vacuum oven before compounding.

\section{Measurements}

Determination of MA grafting content. A standard calibration curve for measuring MA grafting content was first constructed by measuring compression-molded PP films containing different concentrations of 2-dodecen-1-ylsuccinic anhydride on a Nicolet MAGNA-IR 760 Fourier transform infrared spectrometer (Nicolet, Madison, WI, USA). The calibration curve of MA concentration versus anhydride group absorption is shown in Figure 1, in which the peak of $1785 \mathrm{~cm}^{-1}$ corresponds to MA absorption ${ }^{17}$ and the internal standard peak of $460 \mathrm{~cm}^{-1}$ corresponds to PP absorption. These peaks were used to eliminate the influence of film thickness from calculations.

As for the measurement of prepared HMW PP-g-MA samples, unreacted MA was removed by dissolving the sample in hot xylene and then precipitating it in acetone. The MA grafting content of purified HMW PP-g-MA sample film can be obtained after Fourier transform infrared spectrometer measurement using the equation shown in Figure 1.

Gel permeation chromatography. The MW of PP-g-MA extrudate was measured on a high temperature gel permeation chromatography, PL-GPC 220 (Polymer Laboratories, Birmingham, UK). The solvent was 1,2,4-trichlorobenzene with $0.0125 \%$ BHT added to stabilize the polymer against oxidative degradation; the specimen was dissolved at $150^{\circ} \mathrm{C}$ for $24 \mathrm{~h}$. 1,2,4-Trichlorobenzene was used as an eluent at a flow rate of $1.0 \mathrm{ml} \mathrm{min}^{-1}$ at $150{ }^{\circ} \mathrm{C}$.

$X$-ray diffraction. The interlayer spacing of clay was measured by $\mathrm{X}$-ray diffraction (XRD) using a Philips X' Pert MPD X-ray diffractometer (Philips, Almelo, Netherlands) at $40 \mathrm{kV}$ and $40 \mathrm{~mA}$ with a Cu-K $\alpha$ X-ray beam

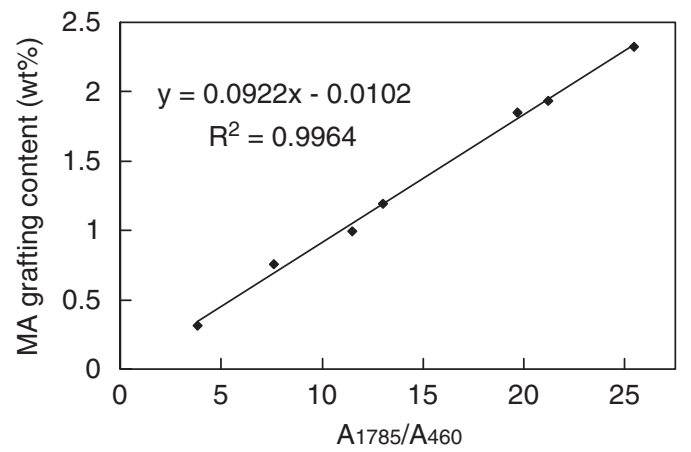

Figure 1 The standard curve used to calculate maleic anhydride (MA) grafting content. $(\lambda=0.15406 \mathrm{~nm})$. The XRD patterns were scanned at small angles $\left(2 \theta=2^{\circ}-10^{\circ}\right)$ to evaluate the intercalation level and clay dispersion. On the basis of Bragg's law, d-spacing (d001) of organoclay platelets was determined from the diffraction angle position (that is, $2 \theta$ ) of the clay (001) at the diffraction peak.

Transmission electron microscopy. The morphology of the clay dispersed in the samples was examined by transmission electron microscopy (TEM) using an FEI Tecnai 20 instrument (FEI, Hillsboro, OR, USA) at an accelerating voltage of $200 \mathrm{kV}$. Ultrathin sections with a thickness of $100 \mathrm{~nm}$ were cryomicrotomed using a LEICA A-1170 microtome (LEICA, Wetzlar, Germany); the sections were not stained.

Rheological measurements. Rheological experiments were carried out on a Rotational Rheometer ARES-2KFRTN1-FCO-HR (TA Instruments, New Castle, DE, USA) with 25-mm-diameter parallel plates used in oscillatory mode at a temperature of $200{ }^{\circ} \mathrm{C}$. A frequency range of $0.063-100 \mathrm{rad} \mathrm{s}^{-1}$ and strains of $5 \%$ were applied during measurement. Test specimens were prepared using compression molding at $210^{\circ} \mathrm{C}$.

\section{RESULTS AND DISCUSSION}

Preparation of HMW PP-g-MA with different MA grafting content and equal MW

The main purpose of this paper was to study the effect of MA grafting content of HMW PP-g-MA on clay dispersion in PPCN. Because PP is susceptible to degradation during melt grafting reactions, and grafting efficiency is low when using only a peroxide initiator and an MA monomer, MW will always be substantially decreased when preparing PP-g-MA with a higher grafting content. Therefore, it is difficult to obtain the required HMW PP-g-MA with the same MW and a different MA grafting content.

In a PP/MA-free radical melt grafting system, the addition of styrene (St) as a comonomer can increase the grafting yield of MA because of the alternating copolymerization of St with MA; ${ }^{18-20}$ in addition, the degradation of PP can also be alleviated. ${ }^{21}$ We thus chose St as the comonomer for the preparation of PP-g-MA and adopted the optimized St-MA molar ratio of $1: 1 .^{20}$

Some preliminary grafting results showed that grafting content and MFR both increased with an increase in DCP concentration, with the latter being more influenced by the DCP concentration. For example, as can be seen in Figure 2, with an increase in DCP loading, MFR rose sharply from $15.8 \mathrm{~g}$ per $10 \mathrm{~min}$ to $134.4 \mathrm{~g}$ per $10 \mathrm{~min}$ when the St and MA loadings were both kept constant at $3 \mathrm{wt} \%$, but MA grafting content increased from 1.41 to $1.73 \mathrm{wt} \%$. According to these grafting results, we carried out a series of grafting experiments by changing the loading of DCP and grafting monomers and successfully prepared two series of PP-g-MA compatibilizers with $M_{\mathrm{w}}$ of approximately 240000 and $190000 \mathrm{~g} \mathrm{~mol}^{-1}$. Their MFR values were around $5 \mathrm{~g}$ per $10 \mathrm{~min}$

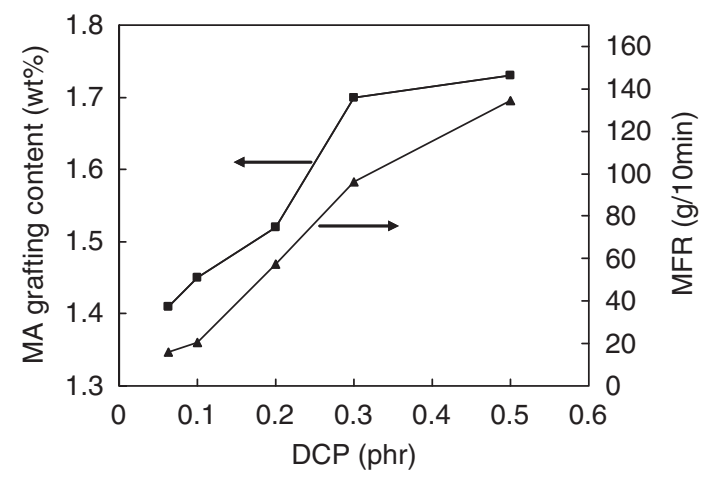

Figure 2 Effect of dicumylperoxide (DCP) loading on melt flow rate (MFR), and maleic anhydride (MA) grafting content of polypropylene-grafted-MA. 
Table 1 Formulations and properties of self-made PP-g-MA compatibilizers

\begin{tabular}{|c|c|c|c|c|c|c|c|c|}
\hline$P P-g-M A$ & $\begin{array}{l}\text { Starting } \\
P P\end{array}$ & $\begin{array}{l}\text { MA loading } \\
\text { (wt\%) }\end{array}$ & $\begin{array}{l}\text { St loading } \\
\text { (wt\%) }\end{array}$ & $\begin{array}{l}\text { DCP loading } \\
\text { (phr) }\end{array}$ & $\begin{array}{c}\text { MFR (g per } \\
10 \mathrm{~min})\end{array}$ & $\begin{array}{l}\text { MA grafting } \\
\text { content (wt\%) }\end{array}$ & $\mathrm{M}_{w}$ & $\mathrm{M}_{n}$ \\
\hline PP5-MA1.4 & TC-1 & 3.0 & 3.0 & 0.07 & 4.0 & 1.41 & 240000 & 56000 \\
\hline PP5-MA0.9 & TC-1 & 1.8 & 1.8 & 0.07 & 5.0 & 0.92 & 245000 & 51000 \\
\hline PP5-MA0.6 & TC-1 & 1.2 & 1.2 & 0.07 & 4.8 & 0.63 & 284000 & 62000 \\
\hline PP5-MA0.2 & TC-1 & 0.4 & 0.4 & 0.07 & 4.5 & 0.20 & 275000 & 59000 \\
\hline PP15-MA0.9 & TC-3 & 1.8 & 1.8 & 0.063 & 15.5 & 0.93 & 187000 & 36000 \\
\hline PP15-MA0.6 & TC-3 & 1.2 & 1.2 & 0.063 & 15.6 & 0.60 & 206000 & 41000 \\
\hline PP15-MA0.2 & TC-3 & 0.4 & 0.4 & 0.063 & 16.2 & 0.22 & 198000 & 36000 \\
\hline
\end{tabular}

Abbreviations: DCP, dicumylperoxide; MA, maleic anhydride; MFR, melt flow rate; PP, polypropylene; St, styrene.

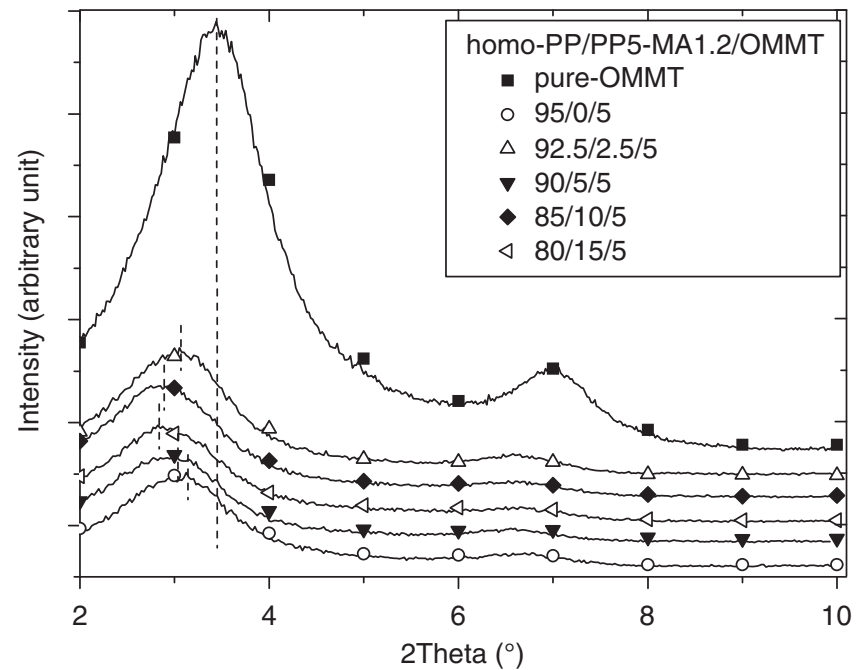

Figure 3 X-ray diffraction patterns of OMMT and some typical PP/ polypropylene-grafted-maleic anhydride (PP-g-MA)-OMMT composites.

and $15 \mathrm{~g}$ per $10 \mathrm{~min}$, respectively (see Table 1 ), which match the respective MFR values of the two PP matrix resins.

PP-g-MA compatibilizer in a homo-PP/OMMT system

The dispersion of OMMT in homo-PP was first investigated using XRD. As seen in Figure 3, the XRD patterns of selected typical composites show similar distinct peaks, which indicates that the intercalation structure is the main structure of OMMT in PP. Their specific $2 \theta$ angles and interlayer spacing are listed in Table 2, according to which the interlayer spacing of pure OMMT is $2.52 \mathrm{~nm}$ before compounding and rises to $2.80 \mathrm{~nm}$ after melt mixing with homo-PP in the absence of compatibilizer. With the addition of different amounts of HMW PP-g-MA, the interlayer spacing increases slightly. The increase in interlayer spacing in the control sample indicates that clay intercalation can occur with the aid of shear force during melt compounding, even in the absence of compatibilizer. This phenomenon has been reported in literature. ${ }^{22,23}$ The interlayer spacing of homo-PP/PP-g-MA/OMMT composites varies slightly with changes in grafting content while maintaining a constant compatibilizer constant loading. The PP-g-MA compatibilizers with a moderate grafting content, that is, between 0.6 and $1.2 \mathrm{wt} \%$, seem to be more effective for clay intercalation compared with other compatibilizers
Table 2 Interlayer spacing of OMMT in homo-PP system derived from XRD patterns

\begin{tabular}{lccc}
\hline Composition & $\begin{array}{c}\text { Grafting content of } \\
\text { PP-g-MA (wt\%) }\end{array}$ & $20\left(^{\circ}\right)$ & $\begin{array}{c}d \text {-spacing } \\
(\mathrm{nm})\end{array}$ \\
\hline OMMT homo-PP/OMMT=95/5 & - & 3.500 & 2.52 \\
(control sample) & - & 3.150 & 2.80 \\
& & & \\
Homo-PP/PP-g-MA/OMMT=92.5/2.5/5 & 0.2 & 3.175 & 2.78 \\
& 0.6 & 3.100 & 2.85 \\
& 0.9 & 3.125 & 2.83 \\
& 1.2 & 3.100 & 2.85 \\
Homo-PP/PP-g-MA/OMMT=90/5/5 & 1.4 & 3.175 & 2.78 \\
& & & \\
& 0.2 & 3.150 & 2.80 \\
Homo-PP/PP-g-MA/OMMT=85/10/5 & 0.6 & 3.075 & 2.87 \\
& 0.9 & 3.050 & 2.90 \\
& 1.2 & 3.050 & 2.90 \\
& 1.4 & 3.100 & 2.85 \\
& & & \\
Homo-PP/PP-g-MA/OMMT=80/15/5 & 0.2 & 3.125 & 2.83 \\
& 0.6 & 2.900 & 3.05 \\
& 0.9 & 2.825 & 3.13 \\
& 1.2 & 2.875 & 3.07 \\
& 1.4 & 3.125 & 2.83 \\
& & & \\
& 0.2 & 3.075 & 2.87 \\
& 0.6 & 2.875 & 3.07 \\
& 1.2 & 3.000 & 2.94 \\
& 1.4 & 2.825 & 3.13 \\
& & 3.05 \\
\hline
\end{tabular}

Abbreviations: homo-PP, polypropylene homopolymers; PP-g-MA, polypropylene-grafted maleic anhydride; XRD, X-ray diffraction.

with lower or higher grafting content, even though their differences are marginal. The effect of loading of PP-g-MA on clay intercalation was also compared. While maintaining a constant grafting content and increasing the loading of PP-g-MA from 2.5 to $15 \mathrm{wt} \%$, the interlayer spacing increased gradually, which indicates that more compatibilizer could penetrate into the clay gallery and thus have a better intercalation effect.

Because XRD is sensitive only to stacked structures, the dispersion of OMMT in PP was also observed using TEM. The TEM micrograph of the control sample (see Figure 4a) shows that OMMT almost all 

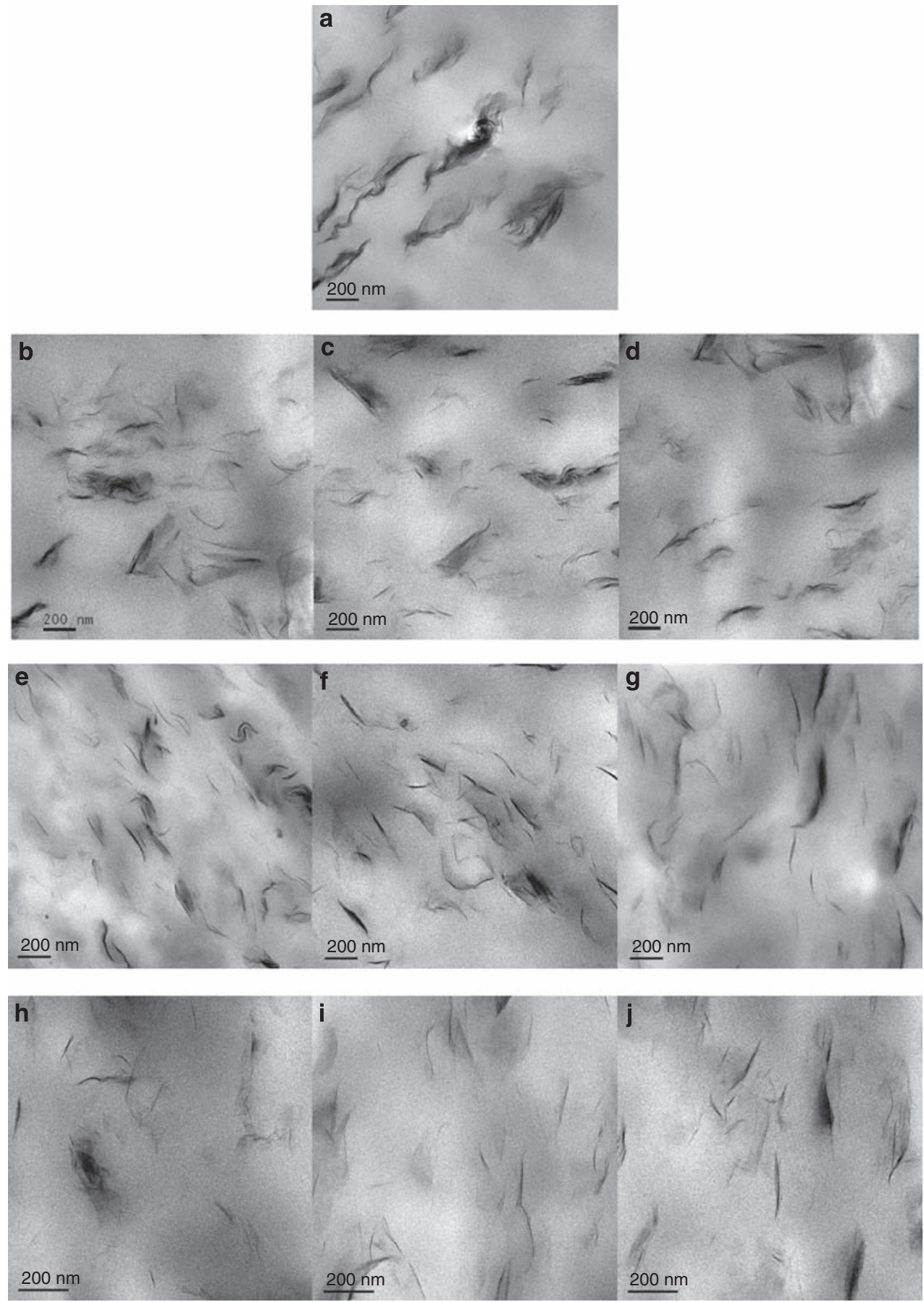

Figure 4 Transmission electron microscopy micrographs of samples in the polypropylene (PP) homopolymer (homo-PP) system. (a) TC-3/OMMT=95/5, (b) TC-3/PPMA-5/OMMT=90/5/5, (c) TC-3/PPMA-4/OMMT=90/5/5, (d) TC-3/PPMA-1/OMMT=90/5/5, (e) TC-3/PPMA-5/0MMT=85/10/5, (f) TC-3/PPMA-4/ OMMT =85/10/5, (g) TC-3/PPMA-1/OMMT=85/10/5, (h) TC-3/ PPMA-5/OMMT=80/15/5, (i) TC-3/PPMA-4/OMMT=80/15/5, (j) TC-3/PPMA-2/OMMT=80/15/5.

forms aggregates without any delaminated platelets. With the incorporation of a small amount (that is, $5 \mathrm{wt} \%$ ) of HMW PP-g-MA, some tactoids and delaminated platelets appeared in the PP matrix, whereas the number of large clay aggregates decreased (see Figures $4 \mathrm{~b}-\mathrm{d}$ ). The delamination degree of OMMT continued to rise as the loading of PPg-MA with the same grafting content increased from 5 to $15 \mathrm{wt} \%$ (compare Figures $4 b, e, h$ and Figures $4 c, f$ and $i$ ), indicating a positive effect of compatibilizer loading on clay delamination and dispersion.
Figures $4 \mathrm{e}-\mathrm{g}$ represent the morphology of composites with the same loading $(10 \mathrm{wt} \%)$ as the compatibilizer but different grafting contents. These three micrographs show a very similar morphology of clay dispersion; that is, tactoids, together with some exfoliated platelets, which indicates that the grafting content of PP-g-MA has no substantial influence on clay dispersion. Other micrographs of composites containing $15 \mathrm{wt} \%$ PP-g-MA with different grafting contents also support this finding, see Figures $4 \mathrm{~h}-\mathrm{j}$. 
Compared with the relatively qualitative evaluation of clay dispersion obtained using TEM, rheological characterization is a rather sensitive quantitative method for analyzing the global state of clay dispersion in PPCN. The melt viscosity of PPCN is related to the network structure due to clay platelets, which is then related to the degree of exfoliation of the clay. Some typical samples are selected for rheological tests; see Figure 4 for their TEM micrographs. As shown in Figure 5, the complex viscosities of homo-PP/OMMT composites increase with the incorporation of PP-g-MA. A significant increase in complex viscosity at a low frequency region can be found when the loading of PP-g-MA increases from 5 to $15 \mathrm{wt} \%$, indicating that compatibilizer loading has a strong influence on clay exfoliation. The viscosities of PPCN at a constant PP-g-MA loading also slightly increase as the grafting content of PP-g-MA increases from 0.2 to $1.4 \mathrm{wt} \%$. From TEM observations, we note that the grafting content of PP-g-MA does not show an appreciable influence on the dispersion of clay, but the rheological results reveal that higher grafting content

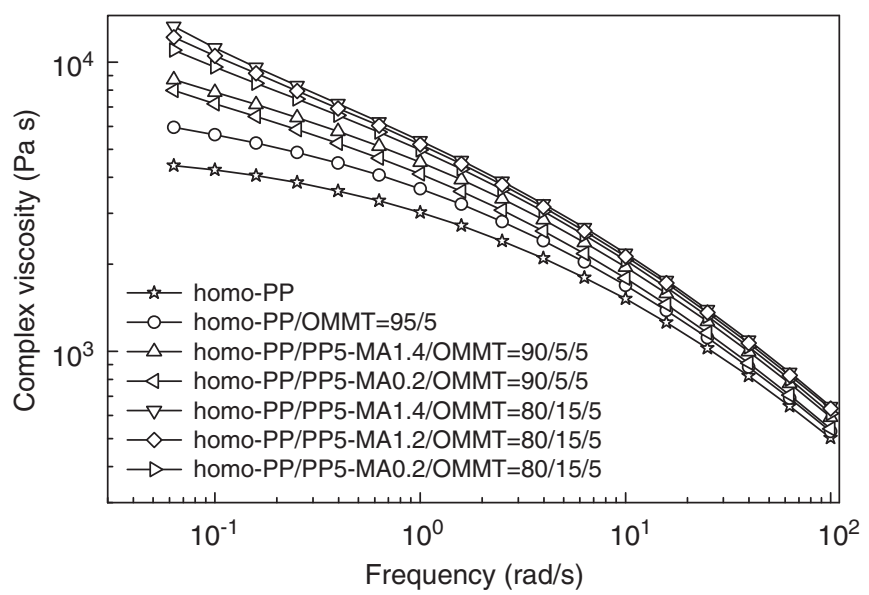

Figure 5 Complex viscosities of some typical polypropylene homopolymer (homo-PP)-OMMT composites. produces a slight improvement in clay dispersion. As for the effect of PP-g-MA loading on clay dispersion, both TEM and rheological results are in good agreement.

To further discuss the effect of grafting content and loading of PP-g-MA compatibilizer on the dispersion of OMMT, we can use a schematic figure (Figure 6) to compare the differences between PP-g-MA oligomer and its counterpart with HMW. Figure 6a shows the oligomer compatibilizer. Because of its low MW and strong interaction between MA and the hydroxyl group on the clay layer, ${ }^{11,12,24}$ the oligomer compatibilizer can easily enter clay galleries and exhibit satisfactory intercalation effects. ${ }^{7,12}$ Figure $6 \mathrm{~b}$ shows that a different situation emerges when using HMW PP-g-MA compatibilizer. The PP5-MA series compatibilizer has an $\mathrm{M}_{\mathrm{w}}$ of around $240000 \mathrm{~g} \mathrm{~mol}^{-1}$, which is much higher than the usual $M_{\mathrm{w}}$ of oligomer. The HMW of this compatibilizer would cause its molecular chain to form larger, random coils during melt compounding processes, which makes it more difficult for the moiety of MA in its molecular chain to diffuse into the clay gallery compared with oligomers. Therefore, the prepared PP5-MA series compatibilizers all show similar, weak intercalation effects, regardless of whether their MA grafting contents are high or low. Although compatibilizers with higher MW do not show a greater intercalation effect because of spatial hindrance, the MA moiety on such compatibilizers is still sufficient for hydrogen bonding ${ }^{11,12,24}$ with hydroxyl groups on the outer surface of clay aggregates. It is also enough to efficiently transfer shear force through the strong hydrogen bonding and its HMW to continuously peel the outer layers of clay aggregates in onion-like delamination. ${ }^{25}$ Therefore, the compatibilizers with HMW still have sufficient exfoliation effects on OMMT.

It should be noted that the St monomer was used in this research for the preparation of two series of PP-g-MA compatibilizers. Li et $a .^{20}$ reported that in the PP/MA grafting system into which equimolar amounts of MA and St were added, the two monomers could easily interact and copolymerize with each other under the initiation of peroxide to form a MA-St (SMA) copolymer chain. The grafting of SMA could yield relatively long branches, and the formation of SMA could also greatly lessen the total number of
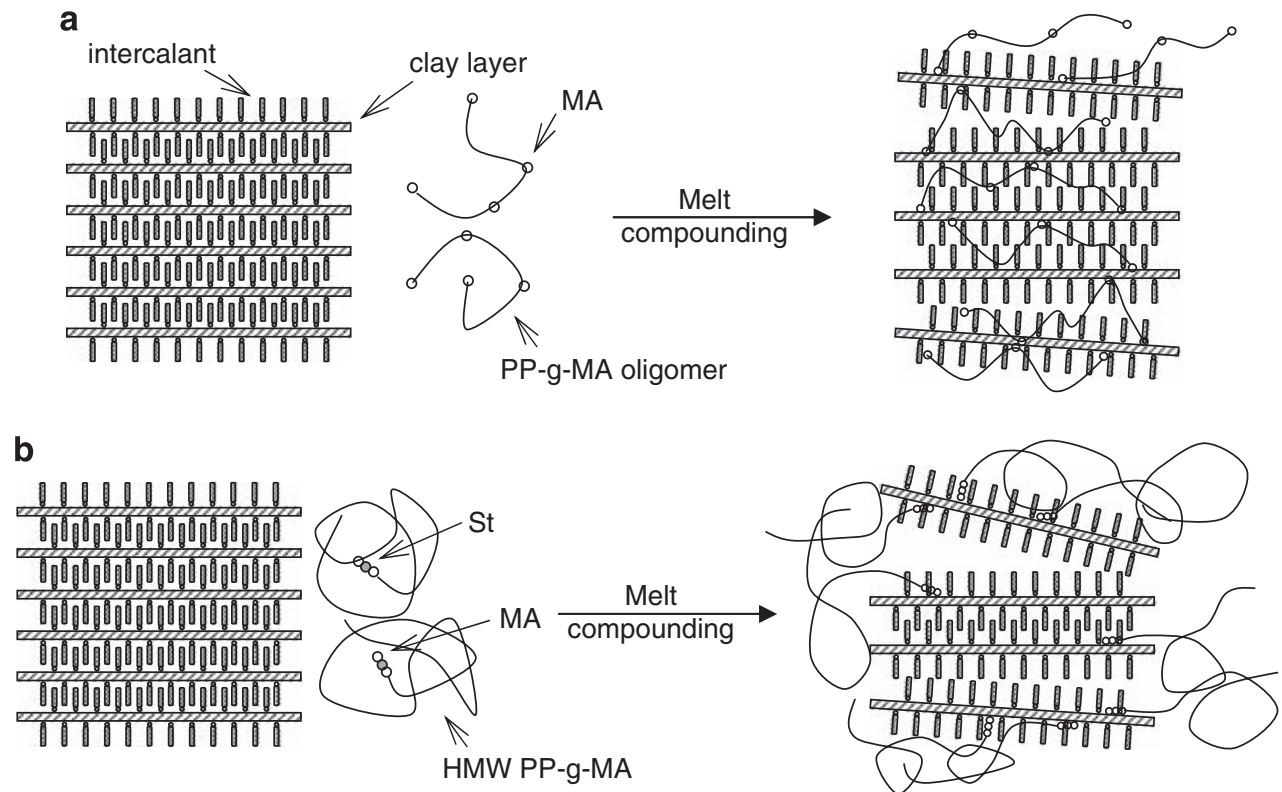

Figure 6 Comparison between the mechanism of clay dispersion using polypropylene-grafted-maleic anhydride (PP-g-MA) oligomer and high molecular weight (HMW) PP-g-MA. 
grafting-reactive species. According to their results, we speculate that, in our PP-MA-St grafting system, the prepared PP-g-MA compatibilizers with different grafting contents differ mainly in the length of SMA rather than in the number of grafting sites, because the loading of initiator DCP was the same in the same series of formulation. Thus, the same amount of DCP should yield the same amount of PP macroradicals, and the MWs of these resulting compatibilizers should be approximately the same. On the basis of these grafting structures, as well as the TEM and rheological results, we may further speculate that one or more succinic anhydride molecules on one grafting site would have slightly different bonding effects between the polar moieties of the PP-g-MA compatibilizer and the outer surface of clay aggregates. PP-g-MA with a higher grafting content may have a longer SMA grafting chain and show slightly stronger bonding with clay layers, resulting in better clay dispersion. However, the difference in bonding effects between longer and shorter SMA grafting chains is not significant because the clay dispersion of PPCN containing the same amount of PP-g-MA with different grafting contents is quite similar according to TEM observations; only rheological results show a slight difference.

As for the effect of compatibilizer loading on clay dispersion, higher compatibilizer loadings indicate more PP-g-MA macromolecules being involved in the intercalation and delamination of clay aggregates. Therefore, a significant delamination effect can be achieved, as confirmed by both TEM and rheological results.

Although the focus of this paper was the study of the effect of PP-MA on clay dispersion, the effects on thermal and tensile properties of PPCN were also measured; they were found to be negligible.

\section{PP-g-MA compatibilizer in a heco-PP/OMMT system}

The HMW PP-g-MA compatibilizer used in the heco-PP system has an MFR of approximately $15 \mathrm{~g}$ per $10 \mathrm{~min}$, which matches the MFR of heco-PP matrix. The effects of grafting content and PP-g-MA compatibilizer loading on the dispersion of OMMT in a heco-PP system were also investigated using XRD and TEM methods. As listed in Table 3, the OMMT interlayer spacing of the heco-PP/OMMT control sample is $2.99 \mathrm{~nm}$, which is larger than that of pure OMMT and also larger than that of the homo-PP/OMMT control sample (Table 2). Because the MFR of heco-PP is higher than that of homo-PP, the relatively smaller random coil of the PP molecular chain in heco-PP may penetrate into clay galleries more easily, thus resulting in larger interlayer spacing.

Similar to the homo-PP system, the incorporation of PP-g-MA further increases the OMMT interlayer spacing in heco-PP/PP-g-MA/ OMMT composites. While maintaining the grafting content of PP-g-MA at each constant level, the interlayer spacing of OMMT increases with increased loading of PP-g-MA. However, while maintaining constant compatibilizer loading, the variation of the grafting content of PP-gMA does not significantly affect the interlayer spacing.

Some TEM micrographs were used to compare the effect of the grafting content and loading of compatibilizer on OMMT dispersion morphology in a heco-PP system. As shown in Figures $7 \mathrm{a}-\mathrm{c}$, OMMT mainly exists in a large aggregate form in the control sample. When the loading of the PP15-MA0.6 compatibilizer was increased, large aggregates turned into small tactoids, and the dispersion of OMMT improved substantially. Figures $7 \mathrm{~d}-\mathrm{f}$ show that grafting content has little influence on the dispersion morphology at 15wt\% PP-g-MA loading. It can also be seen that an intercalated structure predominates in the heco-PP system, whereas in the homo-PP system, an exfoliated structure is the predominant structure at the same loading of PP-g-MA (see Figures $4 \mathrm{f}-\mathrm{h}$ ). As discussed before, HMW PP-g-MA
Table 3 Interlayer spacing of OMMT in heco-PP system derived from XRD patterns

\begin{tabular}{|c|c|c|c|}
\hline Composition & $\begin{array}{c}\text { Grafting content } \\
\text { (wt\%) }\end{array}$ & $2 \theta\left({ }^{\circ}\right)$ & $\begin{array}{c}d \text {-spacing } \\
(n m)\end{array}$ \\
\hline \multirow[t]{2}{*}{ OMMT heco-PP/OMMT=95/5 (control sample) } & - & 3.500 & 2.52 \\
\hline & - & 2.950 & 2.99 \\
\hline \multirow[t]{5}{*}{ Heco-PP/PP-g-MA/OMMT=92.5/2.5/5 } & 0.2 & 2.950 & 2.99 \\
\hline & 0.6 & 2.900 & 3.05 \\
\hline & 0.9 & 2.975 & 2.97 \\
\hline & 1.2 & 2.950 & 2.99 \\
\hline & 1.4 & 2.900 & 3.05 \\
\hline \multirow[t]{5}{*}{ Heco-PP/PP-g-MA/OMMT=90/5/5 } & 0.2 & 2.850 & 3.10 \\
\hline & 0.6 & 2.775 & 3.18 \\
\hline & 0.9 & 2.825 & 3.13 \\
\hline & 1.2 & 2.875 & 3.07 \\
\hline & 1.4 & 2.900 & 3.05 \\
\hline \multirow[t]{5}{*}{ Heco-PP/PP-g-MA/OMMT=85/10/5 } & 0.2 & 2.875 & 3.07 \\
\hline & 0.6 & 2.750 & 3.21 \\
\hline & 0.9 & 2.800 & 3.15 \\
\hline & 1.2 & 2.750 & 3.21 \\
\hline & 1.4 & 2.875 & 3.07 \\
\hline \multirow[t]{5}{*}{ Heco-PP/PP-g-MA/OMMT=80/15/5 } & 0.2 & 2.775 & 3.18 \\
\hline & 0.6 & 2.725 & 3.24 \\
\hline & 0.9 & 2.750 & 3.21 \\
\hline & 1.2 & 2.675 & 3.30 \\
\hline & 1.4 & 2.800 & 3.15 \\
\hline
\end{tabular}

Abbreviations: Heco-PP, polypropylene hetro copolymer; PP-g-MA, polypropylene-grafted maleic anhydride; XRD, X-ray diffraction.

can delaminate OMMT in an onion-like manner. The HMW PP-g-MA compatibilizer used in the homo-PP system has a higher MW than that used in the heco-PP system; therefore, the HMW PP-g-MA in the homo-PP system could transfer stronger shear force and achieve better exfoliation effects. In addition, the melt viscosity of heco-PP should be lower than that of homo-PP because of differences in MFR. Therefore, the weaker shear force in the heco-PP system during melt mixing could also result in a poorer exfoliation effect.

\section{CONCLUSION}

In this study, HMW PP-g-MA compatibilizers with different MA grafting content in the range of $0.2-1.4 \mathrm{wt} \%$ and approximately the same MW were prepared using melt extrusion grafting. The effect of the grafting content and loading of compatibilizers on the dispersion of OMMT in both homo-PP and heco-PP systems was studied without the interference of MW variation in the compatibilizer. Different from PP-g-MA oligomer, HMW PP-g-MA does not enter clay galleries easily and thus shows a poorer intercalation effect. However, HMW PP-g-MA can still effectively delaminate clay layers, given adequate shear force, as well as a strong interaction between its polar MA moieties and outer layers of clay aggregates. In a series of HMW PP-g-MA with different grafting contents, no substantial differences in intercalation effect were found because PP-g-MA molecules with HMW all face similar spatial difficulties when intercalating into clay galleries. The exfoliation effect of HMW PP-g-MA with a high grafting content is slightly better than that with a low 

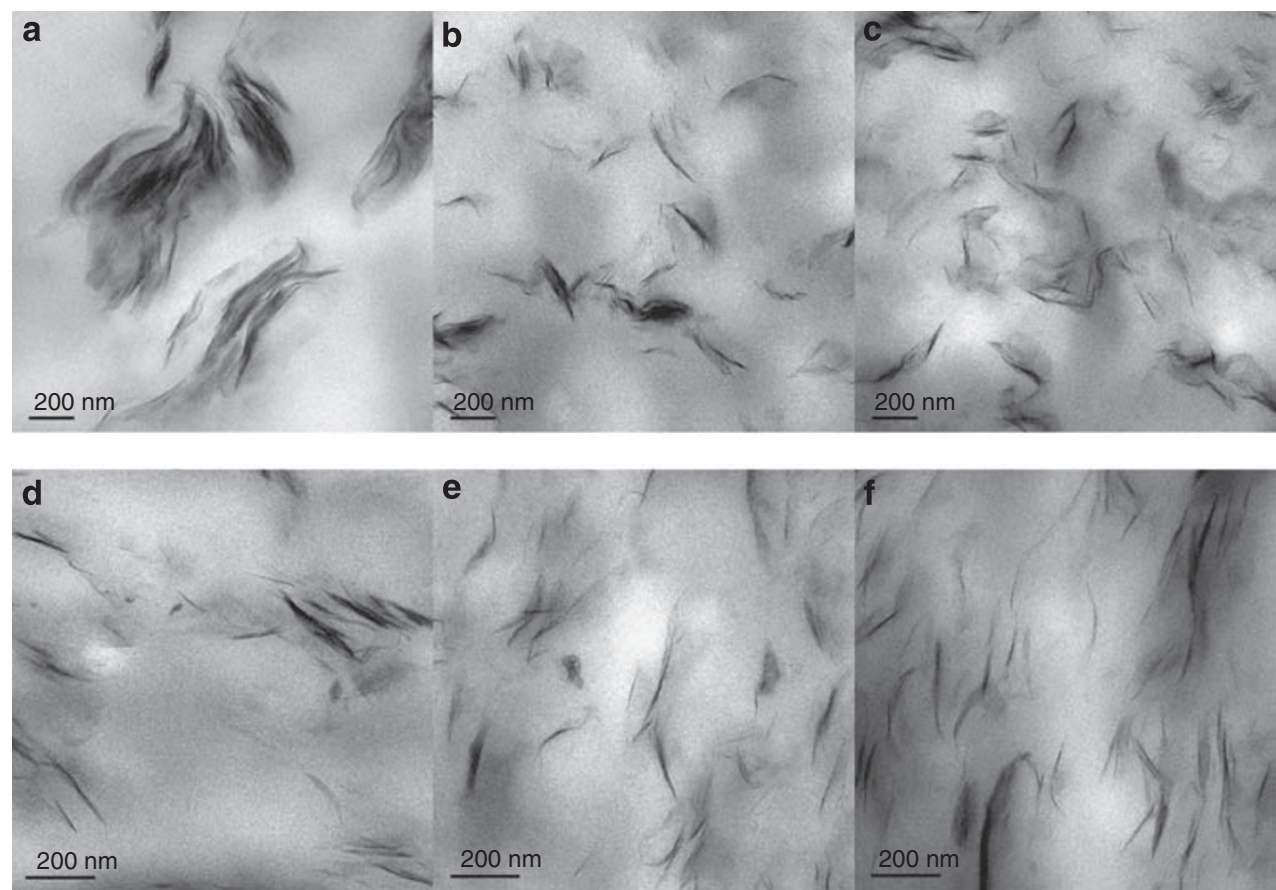

Figure 7 Transmission electron microscopy micrographs of samples in a polypropylene hetro copolymer (heco-PP) system. (a) heco-PP/OMMT=95/5, (b) heco-PP/PP15-MA0.6/OMMT=90/5/5, (c) heco-PP/PP15-MA0.6/OMMT=85/10/5, (d) heco-PP/PP15-MA0.2/OMMT=80/15/5, (e) heco-PP/PP15-MA0.6/ OMMT=80/15/5, (f) heco-PP/PP15-MA1.2/OMMT=80/15/5.

grafting content, but the difference is not appreciable in the range of MA grafting contents used in this study. An increase in PP-g-MA loading can improve the intercalation and exfoliation of OMMT in PP because of the participation of more compatibilizer molecules in intercalation and delamination processes. Through a comparison of two series of HMW PP-g-MA in homo-PP and heco-PP systems, PP-g-MA with a lower MW shows a better intercalation effect, whereas the exfoliation extent of OMMT is mainly influenced by the viscosity of the PP matrix, given a constant compatibilizer loading.

1 Ratnayake, U. N. \& Haworth, B. Polypropylene-clay nanocomposites influence of low molecular weight polar additives on intercalation and exfoliation behavior. Polym Eng Sci. 46, 1008 (2006).

2 Cui, L. L. \& Paul, D. R. Evaluation of amine functionalized polypropylenes as compatibilizers for polypropylene nanocomposites. Polymer. 48, 1632 (2007).

3 Ristolainen, N., Vainio, U., Paavola, S., Torkkeli, M., Serimaa, R. \& Seppala, J. Polypropylene organoclay nanocomposites compatibilized with hydroxyl-functional polypropylenes. J Polym Sci(B). 43, 1892 (2005).

4 Wang, Z. M., Nakajima, H., Manias, E. \& Chung, T. C. Exfoliated PP clay nanocompsoites using ammonium-terminated PP as the organic modification for montmorillonite. Macromolecules. 36, 8919 (2003).

5 Pallay, J., Kelemen, P., Berghmans, H. \& Van Dommelen, D. Poly(propylene)/organoclay nanocomposite formation: influence of compatibilizer functionality and organoclay modification. Macromol Mater Eng. 275, 8 (2000).

6 Marchant, D. \& Jayaraman, K. Strategies for optimizing polypropylene-clay nanocomposite structure. Ind Eng Chem Res. 41, 6402 (2002).

7 Svoboda, P., Zeng, C. C., Wang, H., Lee, L. J. \& David, L. Morphology and mechanical properties of polypropylene/organoclay nanocomposites. J Appl Polym Sci. 85, 1562 (2002).

8 Perrin-Sarazin, F., Ton-That, M. T., Bureau, M. N. \& Denault, J. Micro- and nanostructure in polypropylene clay nanocomposites. Polymer. 46, 11624 (2005).

9 Wang, Y., Chen, F. B., Wu, K. C. \& Wang, J. C. Shear rheology and melt compounding of compatibilized-polypropylene nanocomposites: Effect of compatibilizer molecular weight. Polym Eng Sci. 46, 289 (2006).
10 Wang, Y., Chen, F. B. \& Wu, K. C. Effect of the molecular weight of maleated polypropylenes on the melt compounding of polypropylene organoclay nanocomposites. J Appl Polym Sci. 97, 1667 (2005).

11 Hasegawa, N. \& Usuki, A. Silicate layer exfoliation in polyolefin clay nanocomposites based on maleic anhydride modified polyolefins and organophilic clay. J Appl Polym Sci. 93, 464 (2004)

12 Ton-That, M. T., Perrin-Sarazin, F., Cole, K. C. \& Bureau, M. N. Polyolefin nanocomposites Formulation and development. Polym Eng Sci. 44, 1212 (2004).

13 Xu, W., Liang, G., Wang, W., Tang, S., He, P. \& Pan, W. P. PP-PP-g-MAH-Org-MMT Nanocom- posites: I. Intercalation Behavior and Microstructure. J App/ Polym Sci. 88, 3225 (2003).

14 Dong, Y. \& Bhattacharyya, D. Chlorosulfonated polypropylene preparation and its application as a coupling agent in polypropylene-clay nanocomposites. Compos. A. 39, 1177 (2008).

15 Lim, J. W., Hassan, A., Rahmat, A. R. \& Wahit, M. U. Morphology thermal and mechanical behavior of polypropylene nanocomposites toughened with poly(ethyleneco-octene). Polym Int. 55, 204 (2006).

16 Kato, M., Usuki, A. \& Okada, A. Synthesis of polypropylene oligomer-clay intercalation compounds. J App/ Polym Sci. 66, 1781 (1997).

17 De Roover, B., Sclavons, M., Carlier, V., Devaux, J., Legras, R. \& Momtaz, A. Molecular characterization of maleic anhydride-functionalized polypropylene. J Polym Sci(A). 33, 829 (1995).

18 Chen, X. L., Wu, H., Yu, J., Guo, S. Y. \& Luo, Z. Maleic anhydride_styrene melt grafting and crosslinking onto ethylene-octene copolymer. Polym Eng Sci. 48, 2289 (2008).

19 Rao, H. \& Zhang, Z. Graft copolymerization of maleic anhydridestyrene onto isotactic polypropylene using supercritical $\mathrm{CO}_{2}$. Polym Advan Technol. 19, 770 (2008).

$20 \mathrm{Li}$, Y., Xie, X. M. \& Guo, B. H. Study on styrene-assisted melt free-radical grafting of maleic anhydride onto polypropylene. Polymer. 42, 3419 (2001).

21 Al-Malaika, S. Reactive Modifiers for Polymers, 1st edn. 38.Blackie Academic \& Professional: London, (1997).

22 Lertwimolnun, W. \& Vergnes, B. Influence of compatibilizer and processing conditions on the dispersion of nanoclay in a polypropylene matrix. Polymer. 46, 3462 (2005).

23 Lertwimolnun, W. \& Vergnes, B. Influence of screw profile and extrusion conditions on the microstructure of polypropylene organoclay nanocomposites. Polym Eng Sci. 47, 2100 (2007).

24 Kawasumi, M., Hasegawa, N., Kato, M., Usuki, A. \& Okada, A. Preparation and mechanical properties of polypropylene-clay hybrids. Macromolecules. 30, 6333 (1997).

25 Artzi, N., Nir, Y., Wang, D., Narkis, M. \& Siegmann, A. EVOH/Clay nanocomposites produced by melt processing. Polym Comp. 22, 710 (2001). 